\title{
Quality of Life of Adults Before and After Strabismus Surgery at a Tertiary Care Eye Centre of Kathmandu, Nepal.
}

\author{
Sabina Shrestha, ${ }^{1}$ Aparajita Manoranjan' ${ }^{1}$ and Sushan Shrestha ${ }^{2}$
}

${ }^{1}$ Nepal Eye Hospital, Kathmandu, Nepal ${ }^{2}$, Patan Academy of Health Sciences, Lalitpur, Nepal.

\section{ABSTRACT}

Introduction: Strabismus affects the quality of life of adults both in functional and psychosocial aspect of life. This study was conducted to compare the health related quality of life in adults before and after strabismus surgery.

Methods: It was a prospective quantitative study conducted in Nepal Eye Hospital from Sep 2015 to July 2016.Thirty one adult participants with strabismus undergoing strabismus surgery completed the study. Twenty open ended adult strabismus questionnaire (AS-20) were used to assess the health related quality of life of adults before and one month after strabismus surgery.

Results: The overall median score of adult strabismus questionnaire for quality of life improved from 68.75 (Interquartile range (IQR 25) to 91.25 (IQR 17.5) after strabismus surgery ( $\mathrm{p}$ value $<0.00$ ). Similarly, the median function subscale and median psychosocial subscale also improved from 72 (IQR 25) to 95 (10) and from 55 (IQR 37.5) to 90 (IQR 15) respectively after surgery.

Conclusion: The quality of life of adult strabismic patients improved significantly after stabismus surgery.

Keywords: adults; quality of life; strabismus surgery

\section{INTRODUCTION}

Strabismus and amblyopia affects 2 to $5 \%$ of the pre-school population and is an important cause of visual and psychological disability. ${ }^{1-4}$ Strabismus affects the quality of life including the functional and psychosocial aspects of life of adults. Binocular single vision is required for fine tasks involving stereopsis which is impaired in most of the people with strabismus. Normally eyes should be aligned both in distant and near fixation. Any latent deviation is controlled by the fusional ability of the person. Exophoria more than 9 prism diopters, esophoria more than 7 prism diopters and any amount of hyperphoria are considered abnormal. ${ }^{5}$ However, phoria more than 5 prism diopters horizontally is considered abnormal by others. ${ }^{6}$
Strabismus surgery may be functional that aims to establish or restore binocular single vision or may be indicated to improve ocular alignment in the absence of any potential binocular function. ${ }^{7}$ Surgical correction in strabismus is recommended when the amount of deviation exceeds 20 prism diopters. Deterioration in distant stereo-acuity suggests that surgery may be performed in intermittent exotropia. ${ }^{8}$

This study was conducted to compare the health related quality of life of strabismic adults before and after strabismus surgery.

\section{METHODS}

It was a prospective study conducted in Nepal Eye Hospital from September 2015 to July 2016. Strabismic adults undergoing surgery for the correction of ocular deviation in Nepal Eye Hospital and consenting for the study were

Correspondence: Sabina Shrestha, Nepal Eye Hospital, Kathmandu, Nepal. E-mail: sabina_drs@hotmail.com
This work is licensed under: http:// creativecommons.org/licenses/by-nc-nd/4.0/ 
enrolled. After reviewing the instructions for patients prior to completing the questionnaire, the participants completed adult strabismus questionnaire (AS-20) before surgery and one month after surgery.

Comparison of health related quality of life was done among strabismic adults before and one month after strabismus surgery. Twenty items, patient derived health related quality of life questionnaire developed by Hyatt SR et al was used. The median overall questionnaire score and psychosocial subscale and function subscale score were compared between the participants before and one month after strabismus surgery using Wilcoxon signed-rank test. Similarly, the median difference in the overall, psychosocial and function subscale among male and female and among exotropes and esotropes were compared using Mann-Whitney U test.

\section{RESULTS}

Thirty one adults with strabismus undergoing strabismus surgery completed the study. Among the participants, 18 were females and 13 were males. Age ranged from sixteen to thirty eight years with mean of $23.32+/-6.64$ years.

Twenty four participants had exotropia, six had esotropia and one had hypotropia. One of the participants with exodeviation had third nerve palsy. Associated amblyopia was present in six participants and nystagmus in one participant. Among the exotropes, 21 were manifest and three were intermittent.

The median overall score was 68.75 (IQR 25) among strabismic adults before surgery and was 91.25 (IQR 17.5) after surgery. Median psychosocial scale was 55 (IQR 37.5) before surgery and 90 (IQR 15) after surgery. Similarly, the median function subscale was 75 (IQR 25) before surgery and 95 (IQR 10) after surgery using Wilcoxon signed-rank test. The overall health related quality of life score improved significantly after surgery in strabismic adults ( $p$ value $<0.00$ ). The psychosocial subscale score after surgery improved significantly as compared to before surgery ( $p$ value $<0.00$ ). Similarly, function subscale score also improved significantly after strabismus surgery ( $\mathrm{p}$ value $<0.00$ ).

The median difference in psychosocial subscale before and one month after strabismus surgery was 32.5 (IQR 30) in males and 38.75 (IQR 33.75) in females. Similarly, the median difference in function subscale before and after surgery was ten (IQR 20) in males and 17.5 (IQR 30.63) in females. The difference in median overall score before and one month after surgery was 18.75 (IQR 20) in males whereas it was 26.25 (IQR 23.44) in females by the Mann-Whitney U test.

Among exotropes (IQR $n=24)$, preoperative and one month postoperative difference in median psychosocial score was 36.25 (IQR 33.75), in median function subscale was 17.5 (IQR 21.25) and in overall score was 26.25 (IQR 21.25). Similarly, among esotropes $(n=6)$, preoperative and one month postoperative difference in median psychosocial score was 40 (IQR 35.13), in median function score was 10 (IQR 38.13) and in overall score was 25 (IQR 50) by the Mann-Whitney U test.

\section{DISCUSSION}

Strabismus is known to affect the quality of life in adults. $9,10,11,12,13,14,15,16$ In a comparative study on quality of life of strabismic and non-strabiscmic visually normal adults, there was statistically significant difference in the overall score, psychosocial score as well as function score ( $p$ value 0.00$).{ }^{17}$ Improvement in ocular alignment and restoration of sensory status occurs after surgical treatment of adult strabismus. Ocular alignment is successfully normalized in about $80 \%$ of cases. ${ }^{18,} 1$, 20

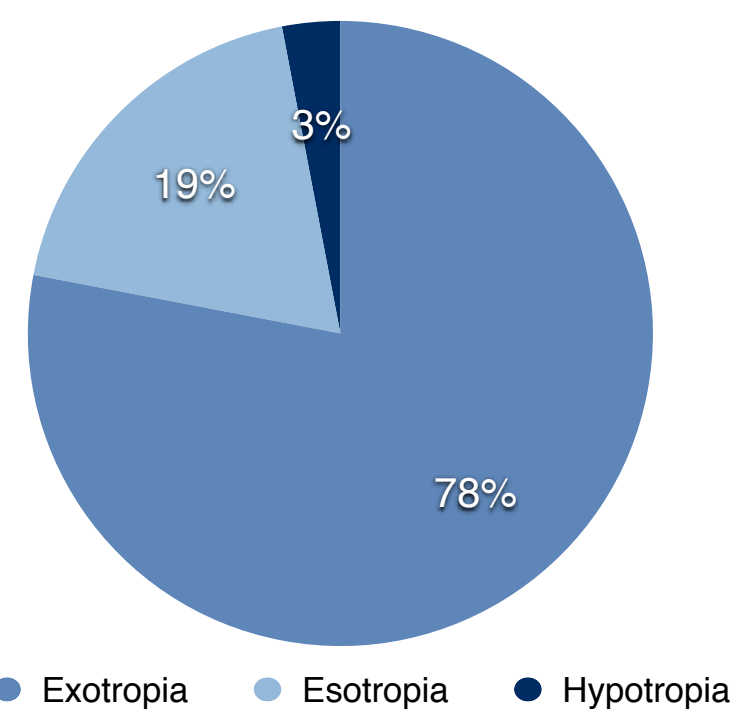

Figure 1: Distribution of types of Strabismus 
However, strabismus surgery in adults can be more challenging than in children and has been quantified by Intensity /Complexity index for strabismus surgery which is higher in cases of adult strabismus. ${ }^{21,22}$ Even dynamic visual field correlated to activities of daily living is improved by strabismus surgery. ${ }^{23}$

The adverse psychosocial sequel of adult strabismus is improved by surgical correction. Measures of psychosocial functioning and comfort with interpersonal communication are enhanced after strabismus surgery. ${ }^{24}$ Apart from that, adult strabismus surgery is highly cost effective, and cost-utility analysis suggest that it has a better value than cataract surgery. ${ }^{25}$

Binocular visual function is improved in adults with strabismus after surgery both in patients with potential for high-grade fusion and those with long standing childhood strabismus. $66 \%-86 \%$ of patients developed at least some degree of binocular fusion after strabismus surgery in several studies. $26,27,28,29,30 \mathrm{Up}$ to $75 \%$ of patients who had strabismus from childhood also demonstrated some degree of fusion after realignment. ${ }^{31,32}$

Patient oriented outcome in medical care is characterized by the quantification of changes in the health related quality of life following treatment. $^{32}$

Strabismus with impairment in visual function and psychosocial function has been identified in recent years and tools like Amblyopia and Strabismus Questionnaire $^{33}$ and 20 item Adult Strabismus Quality of life questionnaire ${ }^{34}$ have been developed.

In the present study also, the overall score of quality of life of strabismic patients improved significantly after surgery. Apart from that, the function subscale and psychosocial subscale also improved significantly after strabismus surgery in adults ( $\mathrm{p}$ value $<0.00$ ). Strabismus surgery in adults, apart from cosmetic value improves the psychosocial and functional aspects of quality of life.

The median difference in quality of life before and after surgery among the males and females and among exotropes and esotropes is not statistically significant in this study. In a study by Shrestha $\mathrm{S}$ et al there was a significant difference in functions of scale between exotropes and esotropes ( $p$ value 0.018 ) while there was no significant difference in psychosocial subscale among exotropes and esotropes. ${ }^{17}$

\section{CONCLUSION}

As health related quality of life significantly improves after strabismus surgery in adults, strabismus surgery needs to be advocated. Psychosocial and functional subscale are improved after strabismus surgery in adult patients whether they are male or female, exotropes or esotropes.

\section{ACKNOWLEDGEMENT}

Authors would like to thank resident doctors of Nepal Eye Hospital for assisting in the in filling up of the questionnaire by the participants. We would also like to acknowledge the extended help of Mr. Karna Deshar for compilation of data.

\section{REFERENCES}

1. Nelson LB, Harley RD. Harley's Paediatric Ophthalmology. 4th Edition Philadelphia: WB Saunders, 1998:146.

2. Chia A. Prevalence of Amblyopia and Strabismus in Young Singaporean Chinese Children. Invest Ophthalmol Vis Sci. 2010 Jul; 51(7): 3411-3417.

https://doi.org/10.1167/iovs.09-4461

3. Varma R, Deneen J, Cotter S, Paz SH et al. Multi-ethnic Pediatric Eye Disease Study Group. Prevalence of amblyopia and strabismus in African American and Hispanic children aged 6 to 72 months. Ophthalmology. 2008;115(7):1229-1236

https://doi.org/10.1016/j.ophtha.2007.08.001

4. Donnelly U, Stewart NM, Hollinger M. Ophthalmic Epidemiol. 2005 Aug;12(4):243-50. Prevalence and outcomes of childhood visual disorders.

\section{https://doi.org/10.1080/09286580590967772}

5. Wong AM, Leuder GT, Burkhalter A, Tychsen L: Anomalous retinal correspondence: neuroanatomic mechanism in strabismic monkeys and clinical findings in strabismic monkeys and clinical findings in strabismic children. JAAPOS 2000; 4:168-174.

https://doi.org/10.1016/S1091-8531(00)70008-5

6. Von Noorden GK, Campos EC. Binocular vision and ocular motility. Theory and management of strabismus. 6th Edition. St. Louis: Mosby, Inc.; 2002:7-37,127-133, 211-245.

7. Morris R. Strabismus surgery. Pediatic Ophthalmology and strabismus. David Taylor, Creig Hoyt. Third edition. Elserver; 2005 962-986. 
8. Alvina Pauline DL Santiago and arther L Rosenbaum. Intermittent exotropia. Pediatric Ophthalmology and Strabismus. Third edition. Elservier; 892-902.

9. Monte D. Mills and Stephen J. Fricker. Adult strabismus. In: Albert \& Jakobiec, Azar, Gragoudas - Principle and Practice of ophthalmology. Vol. 5.2nd ed. Pennsylvania, WB Saunders Company. 2000:4367-79.

10. Mossof RW and Rubin GS. Visual function assessment questionnaires. Surv Ophthalmol 2001; 45:531-548.

\section{https://doi.org/10.1016/S0039-6257(01)00194-1}

11. Van de Graaf ES, van der Sterre GW, Polling JR, et al. Amblyopia and Strabismus Questionaire: design and initial validation. Strabismus 2004; 12:181-193.

\section{https://doi.org/10.1080/09273970490491196}

12. Sabri K, Knapp CM, Thopson JR and Gottlob I. The VF-14 and psychological impact of amblyopia and strabismus. Invest Ophthalmol Vis Sci 2006; 47:4386-4392.

\section{https://doi.org/10.1167/iovs.05-1365}

13. Fumiko Kishimoto, Hiroshi Ohtsuki. Acta Med. Okayama, 1212 vol 66, no.2,101-110.

14. Coats DK, Paysse EA, Tow,er AJ, Dipboye RL. Impact of large angle horizontal strabismus on ability to obtain employment. Ophthalmology 2000:107; 402-5. (18)

15. Satterfield D, Keltner JL, Morrison TB. Psychosocial aspects of strabismus study. Arch Ophthalmol. 1993; 111:1100-5.

https://doi.org/10.1001/archopht. $\underline{1993.01090080096024}$

16. Rogers GL, Chazan S, Fellows R, Tsou BH. Strabismus surgery and its effects upon infant development in congenital strabismus. Ophthalmology. 1982; 89:479-83.

\section{https://doi.org/10.1016/S0161-6420(82)34766-1}

17. Shrestha S, Manoranjan A, Shrestha SM. Comparative study on Quality of life of Strabismic and Non-strabismic Visually Normal Adults. MJSBH January-June 2015/Vol 14/Issue 1.29-32.

18. Caruthers JD, Kennedy RA, Bagaric D. Botulinum vs adjustable suture surgery in the treatment of horizontal misalignment in adult patients lacking fusion. Arch Ophthalmol 4990;108: 1432-1435.

https://doi.org/10.1001/archopht. $\underline{1990.01070120080033}$

19. Mills MD, Coats DK, Donahue SP, Wheeler DT. Strabismus surgery for. Adults. Ophthalmology. 2004;111: 1253-1262. https://doi.org/10.1016/j.ophtha.2004.03.013

20. Hertle RW. Clinical characteristics of surgically treated adult strabismus. J Pediatric Ophthalmol Strabismus. 1998;35:138-145.

21. Beauchamp GR, Black BC, Coats DK, et al. The management of strabismus in adults-l. Clinical characteristics and treatment. JAAPOS. 2003;233-240.

https://doi.org/10.1016/S1091-8531(03)00112-5

22. Black BC, Felius J, Beauchamp GR.AAPOS Outcome and Policy committee. Intensity/ Complexity index of disease for Strabismus surgery. JAAPOS. 2003;7:60-65.

https://doi.org/10.1016/S1091-8531(02)42012-5

23. Kraft SP. Adult Strabismus surgery more than just cosmetic. Can J Opthalmol. 2008; 43:9-12.

https://doi.org/10.3129/i07-211

24. Burke JP, Leach CM, Davis H. Psychosocial implications of strabismus surgery in adults. J Pediatr Ophthalmol Strabismus. 1997; 34:154-164.

25. Beauchamp CL, Beauchamp GR, Stager DR, Brown MM, Brown GC, Felius J. The cost utility of strabismus surgery in adults. JAAPOS. 2006; 10:394-399.

\section{https://doi.org/10.1016/j.jaapos.2006.06.004}

26. Kushner B, Morton G. Postoperative binocularity in adults with long-standing strabismus. Ophthalmology. 1992;99:316-319. Abstract

https://doi.org/10.1016/S0161-6420(92)31970-0

27. Lal G, Homes JM. Postoperative stereoacuity following realignment of chronic acquired strabismus in adults. JAAPOS. 2002;6:233-237. Abstract

https://doi.org/10.1067/mpa.2002.123399

28. Ball A, Drummond GT, Pearce WG, Pearce WG. Unexpected stereoacuity following surgical correction of long-standing horizontal strabismus. Can J Ophthalmol. 1993;28:217-220. Abstract

29. Morris RJ, Scott WE, Dickey CF. Fusion after surgical slignment of long-standing strabismus in adults. Ophthalmology. 1993;100:135-138.

https://doi.org/10.1016/S0161-6420(93)31703-3

30. Scott WE, Kutschke PJ, Lee WR. 20th Frank Costenbader lecture - adult strabismus. J Padiatr Ophthalmol Strabismus. 1995;32:348-352. Abstract

31. Massof RW and Rubin GS: Visual function assessment questionnaire. Surv Ophthalmol (2001) 45:531-548.

https://doi.org/10.1016/S0039-6257(01)00194-1

32. Van de Graaf ES, van der Sterre GW, Polling JR, van kempen-du Saar H, Simonsz B and Simonz 
HJ: Amblyopia and Strabismus questionnaire: design and initial validation. Strabismus (2004)12:181-193.

https://doi.org/10.1080/09273970490491196

33. Hatt SR, Leske DA, Bradley EA, Cole SR and Holmes JM: Comparision of quality- of- life instruments in adults with strabismus. Am J Ophthalmol (2009) 148:558-562.

https://doi.org/10.1016/j.ajo.2009.05.009

34. Sabri K, Knapp CM, Thompson JR and Gottlob 1: The VF-14 and psychological impact of amblyopia and Strabismus. Invest Ophthalmol Vis Sci(2006)47:4386-4392.

https://doi.org/10.1167/iovs.05-1365 